\title{
O ASSOREAMENTO DE UM PEQUENO RESERVATÓRIO - ITIQUIRA, UM ESTUDO DE CASO
}

\author{
Newton de O. Carvalho*, Luiz G. Guilhon e Pedro A. Trindade \\ *ELETROBRÁS/DPE - Rua da Quitanda, 196/22 ${ }^{\circ}$ andar \\ 20091-000 Rio de Janeiro, RJ - Fone (21) 514-5430 Fax (21) 516-4462 \\ newtonc@eletrobras.gov.br
}

\section{RESUMO}

No presente trabalho é apresentado estudo sedimentológico proposto para o projeto básico do reservatório da usina hidrelétrica Itiquira, situada no rio Itiquira, estado do Mato Grosso.

Utilizando-se dados de descarga sólida medidos no local e a curva de retenção de Churchill, indicada para pequenos reservatórios, obtevese uma vida útil efêmera de 12 anos. Além disso, foi aplicada metodologia visando a verificação da evolução do transporte sólido ao longo do tempo, que indicou um crescimento anual de cerca de $16 \%$, que reduziria o tempo de assoreamento do reservatório para apenas 8 anos.

Para garantir a operação da usina foi sugerido o projeto de descarregador de fundo e de desarenador, ambos adequadamente posicionados.

\section{INTRODUÇÃO}

$\mathrm{Na}$ atualidade o Setor Elétrico possui inúmeras pequenas centrais hidrelétricas $(\mathrm{PCH})$ planejadas no horizonte dos próximos 15 anos. Enquanto que no passado, dava-se maior ênfase a aproveitamentos com grandes reservatórios, devido à vantagem da economia de escala, nos dias atuais, os altos custos desses empreendimentos têm levado muitas empresas a procurarem construir usinas com pequenos reservatórios.

Pequenos reservatórios são formados por barragens de porte reduzido que geralmente são construídas no alto curso dos rios, onde existem maiores declividades dos terrenos, fortes precipitações e, em conseqüência, maiores descargas sólidas específicas devido às erosões na área de drenagem. Assim, o comportamento sedimentológico de um pequeno reservatório é, de certo modo, diferente do grande reservatório. Enquanto neste as velocidades da corrente são mais reduzidas, no pequeno reservatório há maiores velocidades e menor capacidade. No grande reservatório se depositam as areias, pedregulhos e parte da carga em suspensão afluente, enquanto no pequeno permanece o sedimento grosso, sendo que o sedimento em suspensão é escoado pelo vertedou- ro e condutos. No entanto o assoreamento se processa mais rapidamente devido a sua pequena capacidade. Então são necessários maiores cuidados na sua proteção, procurando sempre garantir a operacionalidade da tomada d'água para os fins propostos. O controle de sedimento é imperativo.

Neste artigo é descrito estudo sedimentológico realizado para subsidiar o projeto básico da usina hidrelétrica Itiquira, situada no rio Itiquira, Estado do Mato Grosso. O arranjo geral do aproveitamento apresenta barragem e duas casas de força distantes, aproveitando dois desníveis em série (Figura 1). A adução é feita através de canal, sendo que a tomada d'água fica próxima à barragem. O sedimento afluente não poderá ser descarregado automaticamente uma vez que a tomada d'água $(409,0 \mathrm{~m})$ está abaixo do vertedouro (412,0 $\mathrm{m})$.

Além da avaliação do assoreamento do reservatório, que apresenta uma vida útil efêmera, estimada em doze anos, são tecidas considerações sobre o aumento do transporte de sedimentos no curso d'água e apresentada sugestão para inclusão de projeto de descarregador de fundo e de desarenador, ambos adequadamente posicionados, visando viabilizar a operação da usina.

\section{CARACTERÍSTICAS REgIONAIS}

O rio Itiquira nasce no planalto Taquari - Itiquira em altitude próxima de $800 \mathrm{~m}$, no sul do Estado de Mato Grosso, desenvolvendo-se de Leste para Oeste na direção do Pantanal. Em seu trecho superior o rio atravessa terrenos medianamente acidentados e, após a cidade de Itiquira, percorre planalto de relevo suave constituído de solos muito férteis. $\mathrm{Na}$ posição da barragem o rio Itiquira escavou um profundo, estreito e extenso cânion de paredes verticais, numa sucessão de corredeiras, concentrando $220 \mathrm{~m}$ de queda natural.

A jusante do cânion o rio volta a atravessar região de relevo monótono, da depressão Cuiabana, drenando daí suas águas para o Pantanal.

- A cobertura vegetal original era caracterizada por cerrado pouco denso e por matas 


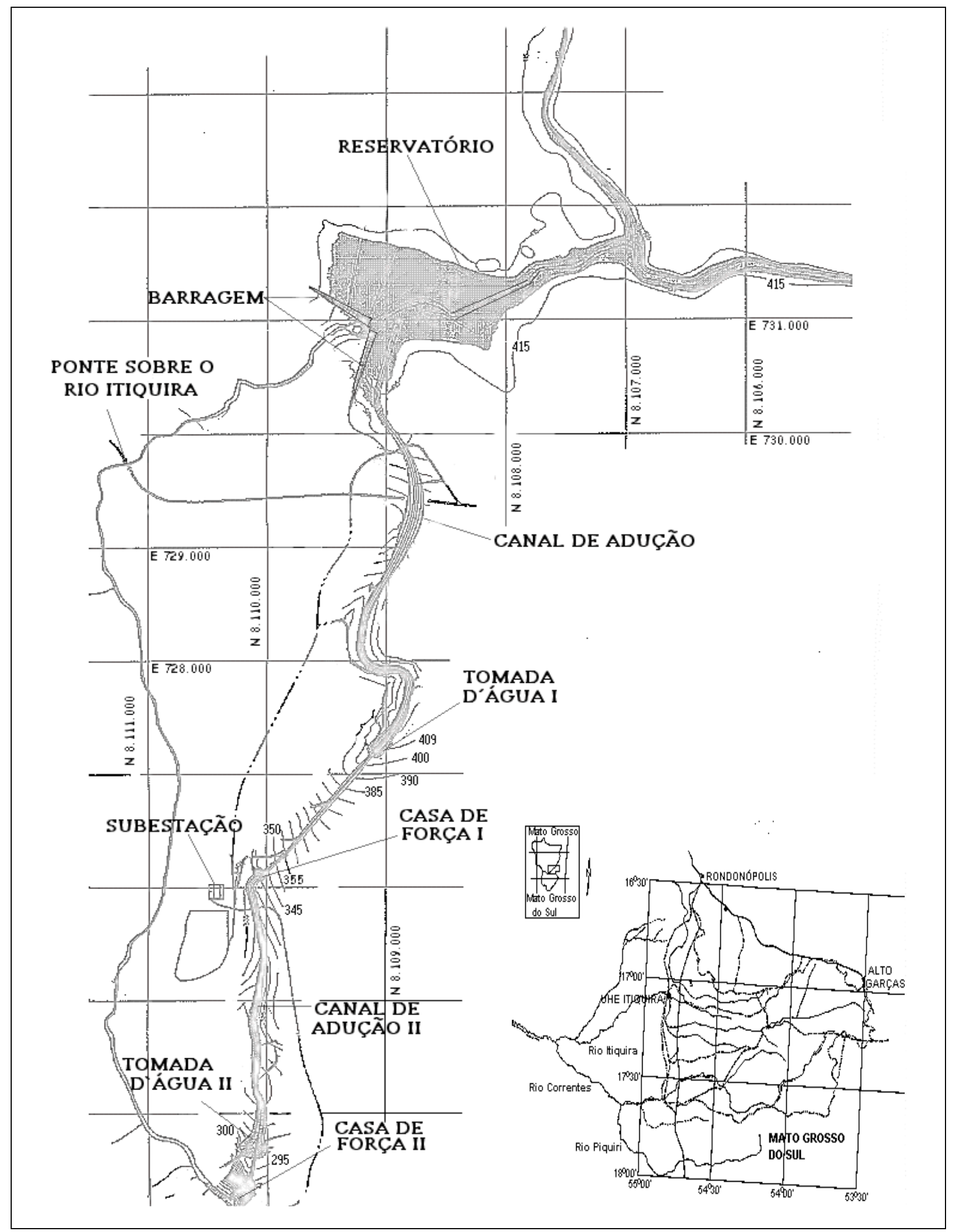

Figura 1. Arranjo geral e localização do aproveitamento hidrelétrico de Itiquira. 
ciliares ao longo das margens dos rios e córregos. Presentemente a vegetação original se manifesta apenas parcialmente na parte superior da bacia e em algumas áreas marginais aos cursos d'água. Principalmente no trecho de relevo suave $\mathrm{e}$ terras férteis a agricultura domina totalmente o uso da terra, sendo a pecuária adotada na serra de São Jerônimo por ser coberta por solos mais pobres, predominantemente arenosos.

- O rio Itiquira drena terrenos sedimentares, principalmente rochas areníticas da Formação Furnas que, pela sua elevada porosidade natural, conferem ao rio um regime hidrológico acentuadamente mais regularizado do que rios com drenagem de semelhantes dimensões em outras formações geológicas (ITICON, 1998).

- Na região do cânion os principais processos erosivos estão associados à ação das águas das chuvas e são incrementados pelos desmatamentos e pelas culturas e pastagens. Locais de exploração de solos, areias, cascalhos e pedras, geralmente exibem extensas áreas degradadas, com formação de sulcos e ravinamentos.

- Os principais processos de deposição de sedimentos carreados pelo rio Itiquira ocorrem principalmente na Depressão do Rio Paraguai, onde as águas mudam de velocidade, provocando deposição de grande quantidade de sedimentos no leito do rio e nas baixadas marginais. Outros processos de deposição de sedimentos são causados por atividades associadas ao garimpo, que provocam o assoreamento de grandes trechos do rio na área do planalto, tal como nas vizinhanças da cidade de Itiquira. (ITICON, 1998).

\section{CLIMA}

A região tem clima quente e sub-úmido, com predominância de temperaturas relativamente elevadas sujeitas a mudanças bruscas no inverno. Devido a altitude, a parte superior da bacia apresenta temperaturas menos elevadas e maiores variações diárias. As temperaturas na bacia apresentam média de $22^{\circ} \mathrm{C}$.

A precipitação média anual é de cerca de $1.400 \mathrm{~mm}$, sendo o trimestre mais chuvoso dezembro / janeiro / fevereiro e o mais seco junho / julho / agosto. Em decorrência disso o rio Itiquira é caracterizado por estiagem entre junho e outubro e um período de descargas mais elevadas de novembro a maio. Apresentando uma descarga média de longo termo de $74 \mathrm{~m}^{3} / \mathrm{s}$, as descargas extremas podem atingir valores de $1300 \mathrm{~m}^{3} / \mathrm{s}$ (milenar) e de $1500 \mathrm{~m}^{3} / \mathrm{s}$ (decamilenar).

\section{OS DADOS SEDIMENTOMÉTRICOS}

O aproveitamento Itiquira foi préinventariado pela EDIBAP, Estudos de Desenvolvimento Integrado da Bacia do Alto Paraguai, um programa de trabalho de cooperação da OEA, Organização dos Estados Americanos, com o Brasil, antes de 1980. A SUDECO, Superintendência de Desenvolvimento do Centro-Oeste, e o DNOS, Departamento Nacional de Obras de Saneamento, ambos extintos, foram as entidades do governo brasileiro que cooperaram com o programa. $\mathrm{Na}$ ocasião foi solicitado ao DNOS a instalação e operação de posto fluvi-sedimentométrico próximo ao local da barragem. O posto instalado foi denominado como Rio Itiquira a Montante da Estrada $B R-163$, tendo sido efetuadas 30 medições de vazão e de descarga sólida, no período de 16/10/79 a 20/03/80, com freqüência mensal, sendo a operação contratada com entidade privada (Tabela 1).

As descargas sólidas medidas foram calculadas pelo método modificado de Einstein (USBR, 1955), tendo esses cálculos sido realizados a partir dos dados de granulometria do material em suspensão e do leito, concentração de sedimentos em suspensão, vazão líquida e outras informações. Foram obtidas, para cada medição, a descarga em suspensão, a descarga total do material do leito e a descarga sólida total. O exame da granulometria do material em suspensão das 30 medições com amostras compostas mostrou que a porção média referente à argila é de $35 \%$, silte de $22 \%$ e que a areia representa $43 \%$. A granulometria do material do leito indicou somente areia e pedregulho, isto é, $100 \%$, mostrando que o sedimento grosso é predominante na carga sólida local.

Os resultados médios das 30 medições indicaram que a descarga sólida de material do leito, isto é, as areias e pedregulhos, representam $54 \%$ da descarga sólida total. Normalmente num reservatório todo o sedimento grosso que entra fica retido, podendo-se considerar que, pelo menos, $50 \%$ de todo o sedimento afluente ao local da barragem será depositado, uma vez que nas enchentes passa alguma areia pelo vertedouro e condutos, descarregando parte do sedimento grosso que poderia permanecer no lago. 
Tabela 1. Medições de descarga sólida no rio Itiquira a montante da estrada BR-163 (DNOS/Hidrologia S. A.).

\begin{tabular}{|c|c|c|c|c|c|c|}
\hline Medição & Data & $\begin{array}{l}\text { Concentr. } \\
\text { Suspensão } \\
\text { (mg/l) }\end{array}$ & $\begin{array}{c}\text { Descarga } \\
\text { Líquida } \\
\left(\mathrm{m}^{3} / \mathrm{s}\right)\end{array}$ & $\begin{array}{c}\text { Descarga } \\
\text { Suspensão } \\
\text { (t/dia) }\end{array}$ & $\begin{array}{c}\text { Descarga } \\
\text { Leito } \\
\text { (t/dia) }\end{array}$ & $\begin{array}{l}\text { Sólida } \\
\text { Total } \\
\text { (t/dia) }\end{array}$ \\
\hline 1 & 16.10 .79 & 207,69 & 95,091 & $1.706,3$ & $2.072,7$ & 3.779 \\
\hline 2 & 14.11 .79 & 263,27 & 58,854 & $1.338,7$ & 766,3 & 2.105 \\
\hline 3 & 8.12 .79 & 94,82 & 51,423 & 421,2 & 504,8 & 926 \\
\hline 4 & 13.01 .80 & 125,95 & 122,995 & $1.338,4$ & $3.555,6$ & 4.894 \\
\hline 5 & 4.02 .80 & 86,99 & 125,020 & 939,6 & $1.299,4$ & 2.239 \\
\hline 6 & 11.03 .80 & 73,98 & 152,241 & 973,1 & $1.255,9$ & 2.253 \\
\hline 7 & 11.04 .80 & 71,52 & 129,786 & 801,9 & $2.251,1$ & 3.053 \\
\hline 8 & 4.05 .80 & 68,15 & 91,818 & 540,6 & $4.535,4$ & 5.076 \\
\hline 9 & 6.06 .80 & 72,61 & 72,979 & 457,8 & $2.356,2$ & 2.814 \\
\hline 10 & 12.07 .80 & 113,62 & 62,631 & 614,8 & $1.048,2$ & 1.663 \\
\hline 11 & 9.08 .80 & 63,23 & 54,270 & 296,4 & 782,6 & 1.079 \\
\hline 12 & 6.09 .80 & 27,85 & 49,046 & 118,0 & 419,0 & 537 \\
\hline 13 & 14.10 .80 & 73,60 & 51,805 & 329,4 & $1.891,6$ & 2.221 \\
\hline 14 & 12.11 .80 & 339,07 & 79,365 & $2.325,0$ & $1.902,0$ & 4.227 \\
\hline 15 & 5.12 .80 & 208,09 & 100,004 & $1.797,9$ & 705,1 & 2.503 \\
\hline 16 & 16.01 .81 & 209,40 & 89,471 & $1.618,7$ & $3.158,3$ & 4.777 \\
\hline 17 & 6.02 .81 & 385,59 & 99.930 & $3.329,1$ & $2.114,9$ & 5.444 \\
\hline 18 & 16.03 .81 & 174,04 & 104,505 & $1.571,4$ & $3.610,6$ & 5.182 \\
\hline 19 & 10.04 .81 & 111,16 & 68,901 & 661,7 & $1.835,3$ & 2.497 \\
\hline 20 & 9.05 .81 & 95,24 & 56,014 & 460,9 & $1.959,1$ & 2.420 \\
\hline 21 & 12.07 .81 & 68,96 & 46,738 & 278,4 & $1.528,6$ & 1.807 \\
\hline 22 & 13.07 .81 & 107,12 & 47,418 & 438,8 & $1.773,2$ & 2.212 \\
\hline 23 & 12.09 .81 & 132,00 & 45,921 & 523,7 & $1.881,3$ & 2.405 \\
\hline 24 & 13.09.81 & 112,03 & 43,234 & 418,4 & 331,6 & 750 \\
\hline 25 & 24.11 .81 & 349,96 & 159,384 & $4.819,2$ & 880,8 & 5.700 \\
\hline 26 & 25.11 .81 & 366,83 & 150,980 & $4.785,1$ & 335,9 & 5.121 \\
\hline 27 & 28.01 .82 & 445,96 & 148,119 & $5.707,1$ & $2.892,9$ & 8.600 \\
\hline 28 & 29.01 .82 & 368,78 & 140,167 & $4.466,0$ & 289,0 & 4.755 \\
\hline 29 & 19.03 .82 & 371,20 & 103,120 & $3.307,2$ & $4.572,8$ & 7.880 \\
\hline 30 & 20.03 .82 & 352,04 & 101,022 & $3.072,7$ & $4.777,3$ & 7.850 \\
\hline
\end{tabular}

\section{AVALIAÇÃO dO ASSOREAMENTO E DA VIDA ÚTIL DO RESERVATÓRIO}

A avaliação do assoreamento do volume total do reservatório e da vida útil do aproveitamento é essencial no respectivo projeto. O final da sua vida útil, do ponto de vista sedimentológico, é considerado quando os depósitos passam a perturbar a operação regular da usina ou da finalidade para a qual foi formado o reservatório. Outras avaliações são feitas para o cálculo do assoreamento de um reservatório, como sejam, o tempo para que o sedimento alcance a soleira da tomada d'água (vida útil), a distribuição de sedimentos ao longo do reservatório correspondente a determinados tempos e a formação do delta (declividade superior e declividade frontal). Para essas previsões são necessários dados de projeto e dados sedimentométricos. No presente artigo são efetuados somente os primeiros estudos acima indicados.

A obtenção da descarga do leito é fundamental para os estudos de previsão do assoreamento de um pequeno reservatório como se verá neste estudo de caso.

A seguir são relacionados os principais dados do reservatório de Itiquira (ITICON, 1998):

Nível d'água máximo normal Nível d'água mínimo normal Volume no N.A. máx. normal Volume no N.A. mín. normal Volume morto

Vazão média de longo termo Cota da soleira do vertedouro Cota da soleira da tomada d'água Comprimento do reservatório

Os dados sedimentométricos são apresentados na Tabela 1. Para cálculo de assoreamentos utilizam-se as seguintes expressões: 


$$
\begin{gathered}
S=\frac{D_{\text {st }} \times E_{r}}{\gamma_{\text {ap }}}=\frac{365 Q_{s t} \times E_{r}}{\gamma_{a p}} \\
T=\frac{V_{\text {res }}}{S}
\end{gathered}
$$

sendo $\mathrm{S}$ o volume de sedimento retido no reservatório ( $\left.\mathrm{m}^{3} / \mathrm{ano}\right) ; \mathrm{D}_{\mathrm{st}} \mathrm{O}$ deflúvio sólido total médio afluente ao reservatório (t/ano); $E_{r}$ a eficiência de retenção do sedimento afluente ao reservatório (fração); $\gamma_{\mathrm{ap}}$ o peso específico aparente médio dos depósitos $\left(\mathrm{t} / \mathrm{m}^{3}\right) ; \mathrm{Q}_{\mathrm{st}}$ a descarga sólida total afluente (t/ano); T o tempo de assoreamento de um determinado volume (anos) e $V_{\text {res }}$ o volume do reservatório, total ou volume morto $\left(\mathrm{m}^{3}\right)$.

Normalmente, o valor de $\mathrm{D}_{\mathrm{st}}$ adotado na avaliação do assoreamento de um reservatório e da sua vida útil, deve ser o dobro do observado, visando levar em conta um provável aumento da carga sólida com o tempo, devido a ações antrópicas na bacia. Tendo-se dados sedimentométricos para vários anos de medições, pode-se avaliar adequadamente a taxa anual de aumento da carga sólida derivada da erosão na bacia. Esse assunto será tratado neste artigo.

A seguir são relatadas as formas de obtenção dos parâmetros necessários aos cálculos do volume de sedimento retido $\mathrm{S}$ e do tempo de assoreamento $T$.

\section{Definição da curva-chave de sedimentos}

Os dados de vazão e descarga sólida total, mostrados na Tabela 1, foram processados, inicialmente, visando o estabelecimento de lei de correlação através do método dos mínimos quadrados. O procedimento não se mostrou adequado pois conduziu a expressão matemática não representativa da realidade física do fenômeno. Isso significa dizer que, num gráfico de escalas lineares, a curva interpolada apresentaria concavidade voltada para cima, além de fornecer valores de descarga sólida negativos para águas baixas. Uma análise mais detida indicou que essa inadequação era devida à configuração dos pontos relativos a descargas sólidas inferiores a $1.100 \mathrm{t} / \mathrm{dia}$, que se apresentaram inconsistentes devido, provavelmente, a imprecisões cometidas nos processos de coleta e/ou análise de amostras de sedimentos correpondentes a essas descargas. Para contornar esse problema, procedeu-se a uma criteriosa interpolação a sentimento, na qual os pontos supracitados foram desconsiderados. Disso resultou o gráfico apresentado na Figura 2.

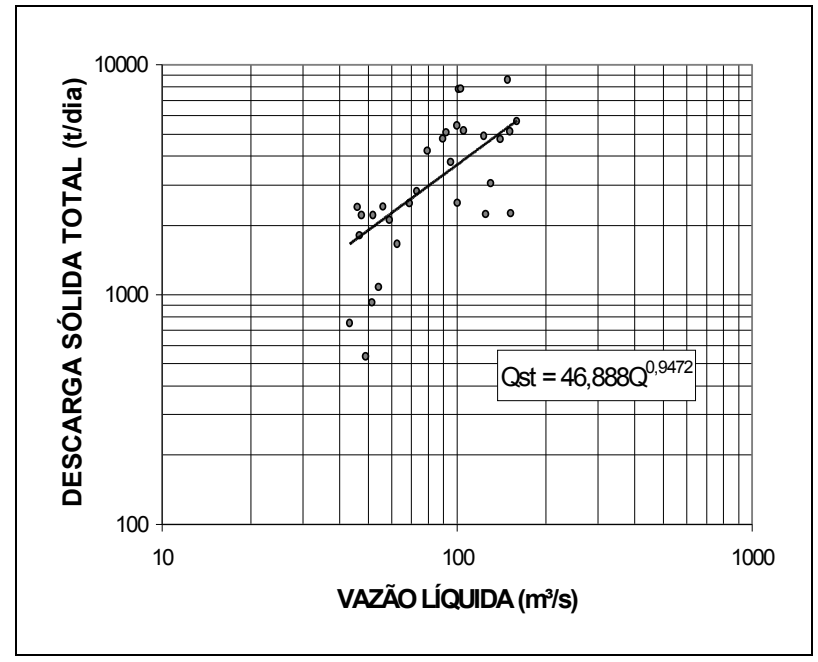

Figura 2. Curva-chave de sedimentos totais do rio Itiquira, a montante da estrada BR-163 (período 1979/1982).

Deve-se salientar que, no estabelecimento de curvas-chave de sedimentos, diferentes procedimentos podem ser seguidos, como seja, adotar duas curvas, uma para o período úmido e outra para o período seco. Outra técnica, recomendada por alguns autores, é a da utilização das concentrações, $C=f(Q)$, no lugar de $Q_{s}=f(Q)$.

No presente estudo, contudo, a aplicação dessas e de outras metodologias, não conduziram a resultados sensivelmente diferentes. Dependendo do caso, todavia, seu emprego poderá resultar em correlações mais representativas, especialmente quando se dispõe de um número de medições maior do que se pôde contar no presente estudo.

\section{Obtenção do deflúvio sólido afluente}

Utilizando a série de vazões do período 1931/1997 e a equação da curva-chave:

$$
\mathrm{Q}_{\mathrm{st}}=46,888 \mathrm{Q}^{0,9472}
$$

obteve-se a série de descargas sólidas totais do mesmo período. A descarga sólida total média do período corresponde a $2.715 \mathrm{t} / \mathrm{dia}$. Os valores de $Q_{\text {st }}$ e $D_{\text {st }}$ são:

$$
Q_{\text {st }}=2.715 \mathrm{t} / \mathrm{dia}
$$

$$
D_{s t}=2.715 \times 365 \text { dias }=990.975 \text { t/ano }
$$




\section{Obtenção da eficiência de retenção}

O valor da eficiência de retenção de sedimentos num reservatório pode ser obtido a partir de medições sistemáticas da descarga sólida afluente e a jusante da barragem. No caso de estudos anteriores à construção da barragem utilizam-se curvas obtidas a partir de levantamentos de reservatórios existentes. Para médios e grandes reservatórios utiliza-se a curva de Brune e para pequenos adota-se a curva de Churchill.

A curva de Brune apresenta no eixo das ordenadas o valor da eficiência de retenção de sedimentos no reservatório, em porcentagem ou em fração, e no eixo das abscissas a capacidade de afluência, correspondendo esta ao volume do reservatório dividido pelo deflúvio médio anual afluente. Usa-se o volume do reservatório correspondente ao nível d'água máximo normal. Essa curva de Brune pode ser obtida em Carvalho (1994), Morris/Fan (1997), Strand (1974) ou Vanoni (1977).

A curva de Churchill é apresentada em três versões, necessitando-se de cuidados no seu uso, resultando em igual valor de retenção seja qual for a curva utilizada. Em qualquer uma delas, o eixo das ordenadas representa a porcentagem do sedimento afluente que passa para jusante da barragem. Assim, a eficiência de retenção é obtida por diferença com $100 \%$ e deve ser expressa em fração para efeito de cálculo.

Para efeito de comparação e possível uso pelo leitor são apresentadas a seguir as versões das curvas.

A curva de Churchill incluída em Morris/Fan (1997), Strand (1974) ou Vanoni (1977) é ilustrada na Figura 3. Nela o eixo das abscissas corresponde ao valor do Índice de Sedimentação do Reservatório IS que é igual ao período de retenção dividido pela velocidade média no reservatório. Esses parâmetros são calculados da seguinte forma:

- Período de retenção = volume do reservatório $\left(\mathrm{m}^{3}\right)$ dividido pela vazão média diária durante o período de estudo $\left(\mathrm{m}^{3} / \mathrm{s}\right)$;

- Velocidade média no reservatório = vazão média diária $\left(\mathrm{m}^{3} / \mathrm{s}\right)$ dividido pela área da seção transversal média $\left(\mathrm{m}^{2}\right)$. A área da seção transversal média pode ser determinada pela divisão do volume do reservatório pelo seu comprimento (m).

O volume do reservatório corresponde à capacidade no nível médio de operação. Os pequenos reservatórios geralmente operam a fio d'água, sendo esse o volume correspondente a ser utilizado. Deduzindo as informações acima, chegase à seguinte expressão para o Índice de Sedimentação a ser utilizada nessa versão da curva de Churchill (Figura 3):

$$
\text { IS }=\frac{\text { Período de retenção }}{\text { Velocidade média }}=\frac{V_{\text {res }}{ }^{2}}{Q^{2} \cdot L}
$$

sendo IS o índice de sedimentação do reservatório; $\mathrm{V}_{\text {res }}$ o volume do reservatório no nível médio de operação $\left(\mathrm{m}^{3}\right)$; $\mathrm{Q}$ a vazão afluente média diária durante o período de estudo $\left(\mathrm{m}^{3} / \mathrm{s}\right)$ e $\mathrm{L}$ comprimento do reservatório $(\mathrm{m})$.

Uma outra versão da curva de Churchill, apresentada em ICOLD (1989), tem no eixo das ordenadas, na parte superior do desenho, o índice de sedimentação de Churchill multiplicado pela aceleração da gravidade $\mathrm{g}$, sendo:

$$
\text { IS.g }=\frac{V_{\text {res }}^{2} \cdot g}{Q^{2} \cdot L}
$$

Uma terceira versão da curva de Churchill, modificada por Roberts, que é apresentada em Annandale (1987), foi a utilizada no presente trabaIho. Nesse gráfico (Figura 4), o eixo das ordenadas é expresso conforme a equação abaixo, onde os cálculos para o caso em estudo se encontram indicados.

$$
\text { IS.g }=\frac{g \cdot V_{\text {res }}{ }^{2}}{Q^{2} \cdot L}=\frac{9,8 \times\left(4,8 \times 10^{6}\right)^{2}}{(72,9)^{2} \times 5 \cdot 600}=7,6 \times 10^{6}
$$

De acordo com o exposto, a carga sólida em suspensão é composta de $43 \%$ de areias e a carga sólida do leito, de $100 \%$ de areias e pedreguIhos que são sedimentos que normalmente ficam depositados no reservatório, tendo dificuldade de sair pelo vertedouro e condutos.

Analisando a Tabela 1, pode-se observar que a descarga sólida de material do leito corresponde a $54 \%$ da descarga sólida total.

Entrando na curva de Churchill, obtida de Annandale (1987), com o valor de IS calculado, tem-se que o sedimento que sai do reservatório corresponde a $55 \%$, sendo depositado, consequentemente, $45 \%$ do sedimento afluente. Considerando que essa curva é experimental, um valor de $50 \%$ seria perfeitamente coerente para o valor da eficiência de retenção, pois situa-se entre o valor de $54 \%$ da porção da carga de material do leito e os $45 \%$ da curva de Churchill. Dessa forma confirmou-se o que parecia evidente, adotando-se, então, $\mathrm{E}_{\mathrm{r}}=50$. 


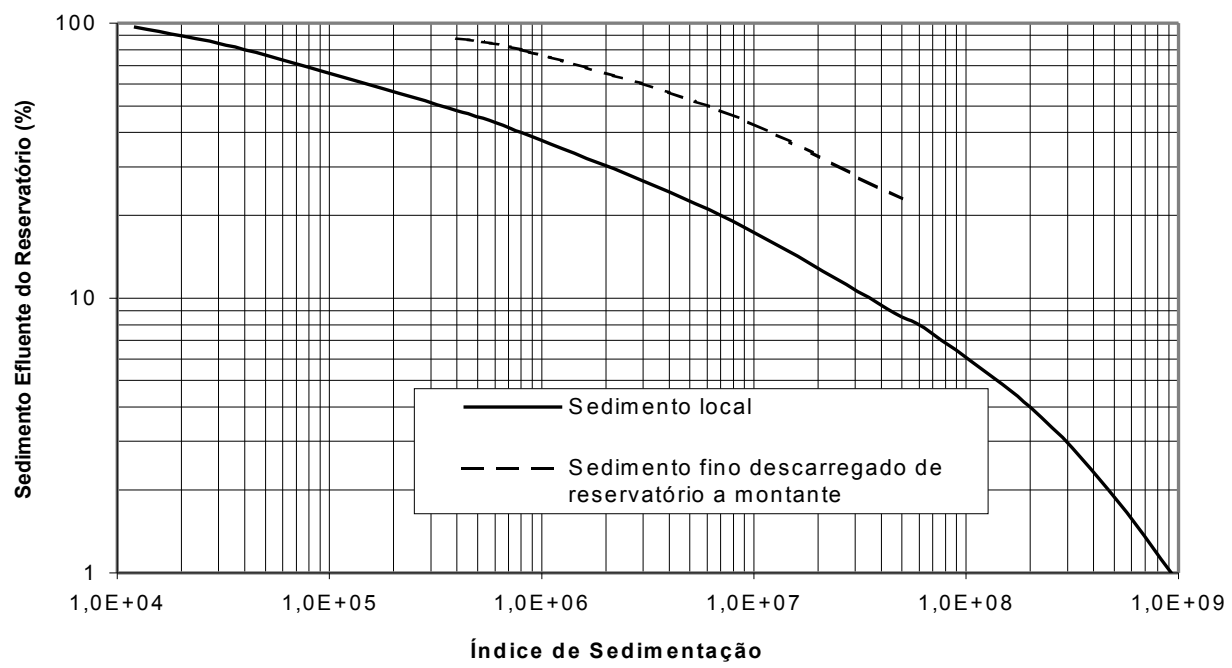

Figura 3. Retenção de sedimentos no reservatório de acordo com Churchill (Vanoni, 1977).

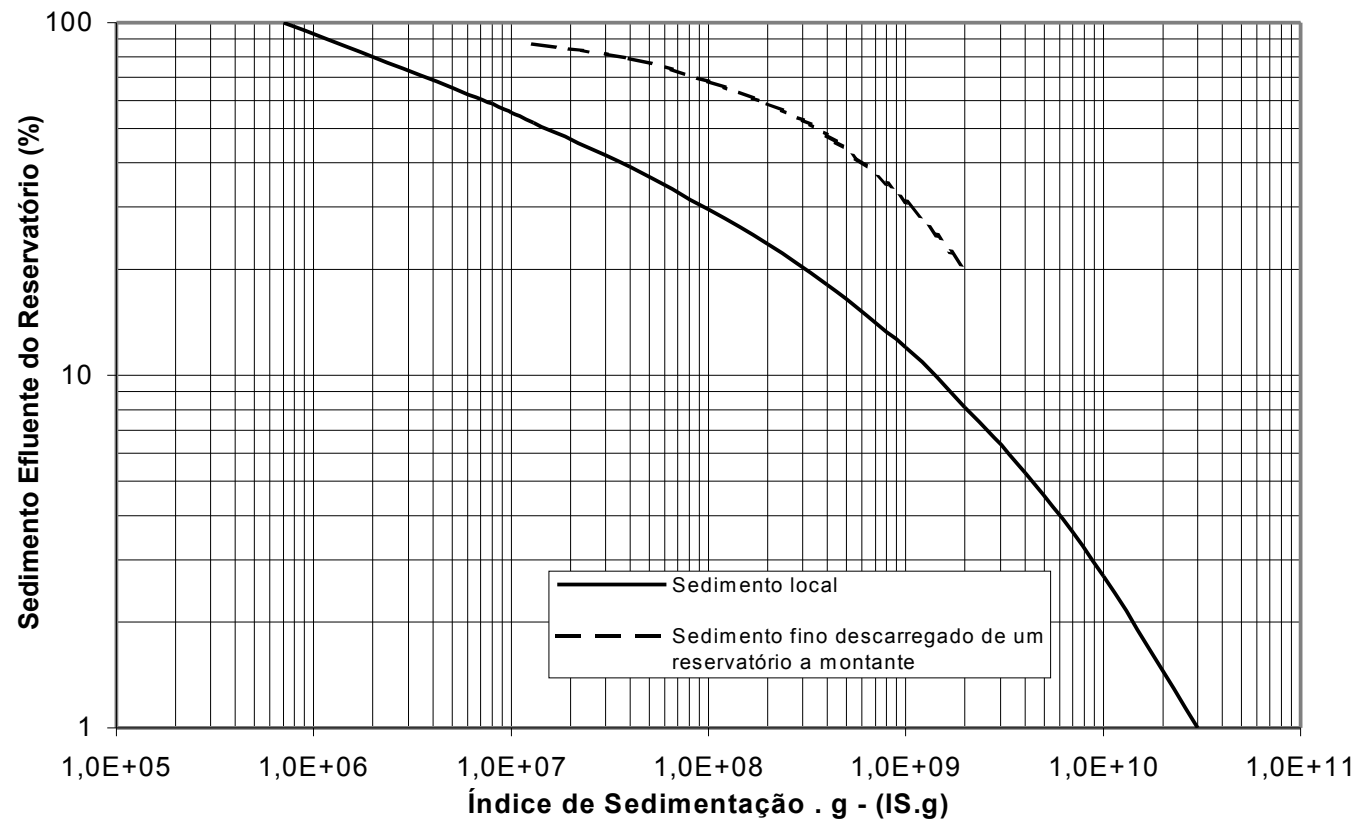

Figura 4. Retenção de sedimentos no reservatório de acordo com Churchill (Annandale, 1987).

\section{Peso específico aparente}

O deflúvio sólido é geralmente calculado em termos de peso por tempo, como t/ano, devendo ser transformado em volume equivalente, como $\mathrm{m}^{3}$ /ano, através do conhecimento do peso específi- co aparente. Lara e Pemberton, segundo apresentado por Carvalho (1994), Strand (1974), Vanoni (1977) e outros autores, chegaram à conclusão através de pesquisas com amostragem em reservatórios existentes, que o peso específico aparente dos depósitos de sedimento pode ser calculado segundo o tipo de operação desse reser- 
vatório, o grau de compactação dos sedimentos e a granulometria, fatores esses que mais influenciam na consolidação dos depósitos. Outros fatores de menor influência podem ser citados, como a densidade de correntes de sedimento no reservatório, a declividade do talvegue do curso d'água afluente e o efeito da vegetação na área das cabeceiras do reservatório.

O cálculo do peso específico aparente foi, então, efetuado pelas equações a seguir, cujos fatores das parcelas serão obtidos segundo o tipo de operação do reservatório (Tabela 2):

$$
\begin{gathered}
\gamma_{i}=W_{c} \cdot P_{c}+W_{m} \cdot P_{m}+W_{s} \cdot P_{s} \\
\gamma_{T}=\gamma_{i}+K \cdot \log T \\
\text { ou } \\
\gamma_{T}=\gamma_{i}+0,4343 \cdot K\left[\frac{T}{T-1}(L n T)-1\right] \\
K=K_{c} \cdot P_{C}+K_{m} \cdot P_{m}+K_{s} \cdot P_{S}
\end{gathered}
$$

sendo $\gamma_{i} \circ$ peso específico aparente inicial $\left(\mathrm{t} / \mathrm{m}^{3}\right)$; $\mathrm{W}_{\mathrm{c}}, \mathrm{W}_{\mathrm{m}}, \mathrm{W}_{\mathrm{s}}$ os coeficientes de compactação de argila, silte e areia, respectivamente, obtidos segundo o tipo de operação do reservatório (Tabelas 2 e 3); $P_{c}, P_{m}, P_{s}$ as frações de quantidades de argila, silte e areia contidas no sedimento afluente; $\gamma_{T}$ o peso específico aparente médio em $T$ anos $\left(\mathrm{t} / \mathrm{m}^{3}\right)$; T o tempo de compactação do sedimento depositado (anos); $\mathrm{K}$ a constante que depende da granulometria do sedimento e obtida com base no tipo de operação do reservatório (Tabela 3) e Ln o logaritmo neperiano.

Os valores dos coeficientes $\gamma_{i}, \gamma_{T}$ e K apresentados por Strand foram transformados para uso no sistema métrico (Carvalho, 1994).

Para utilização das equações e respectivas tabelas é necessário ter as porcentagens médias de argila, silte e areia contidas nos sedimentos em suspensão e do leito, bem como as porcentagens da descarga sólida em suspensão média e descarga sólida média do leito e em seguida, fazer a composição necessária para o conhecimento das porcentagens de argila, silte e areia (material grosso) referentes à descarga sólida total.

Para cálculo de $\gamma_{i}$ e $\gamma_{T}$, no presente caso, conforme os dados antes indicados, chega-se à conclusão que todo o material fino (a argila e o silte) sai pela barragem (vertedouro e condutos), não ficando depositado no reservatório. Assim, a areia representa $100 \%$ de sedimento depositado. Substituindo nas fórmulas acima e considerando a
Tabela 2. Tipo de operação de reservatório (adaptado de Strand, 1974).

\begin{tabular}{cl}
\hline Tipo & Operação do reservatório \\
\hline 1 & $\begin{array}{l}\text { Sedimento sempre ou quase sempre } \\
\text { submerso } \\
\text { Depleção do reservatório de pequena a } \\
\text { média }\end{array}$ \\
3 & $\begin{array}{l}\text { Reservatório de significativas variações } \\
\text { de nível } \\
\text { Reservatório normalmente vazio }\end{array}$ \\
\hline
\end{tabular}

Tabela 3. Constantes $W$ e $K$ para cálculo do peso específico aparente em função do tipo de operação do reservatório para uso no sistema métrico (adaptado de Strand, 1974).

\begin{tabular}{cccccc}
\hline Tipo & \multicolumn{2}{c}{ Argila } & \multicolumn{2}{c}{ Silte } & \multicolumn{2}{c}{ Areia } \\
& $\mathrm{W}_{\mathrm{c}}$ & $\mathrm{K}_{\mathrm{c}}$ & $\mathrm{W}_{\mathrm{m}}$ & $\mathrm{K}_{\mathrm{m}}$ & $\mathrm{W}_{\mathrm{s}}$ \\
\hline 1 & 0,416 & 0,2563 & 1,121 & 0,0913 & 1,554 \\
2 & 0,561 & 0,1346 & 1,137 & 0,0288 & 1,554 \\
3 & 0,641 & 0,0000 & 1,153 & 0,0000 & 1,554 \\
4 & 0,961 & 0,0000 & 1,169 & 0,0000 & 1,554 \\
\hline
\end{tabular}

Obs: As constantes K para areias são nulas para todos os tipos de operação.

operação do reservatório como sendo do tipo 1, com sedimento sempre ou quase sempre submerso, tem-se:

$\gamma_{i}=0,416 \times 0,0+1,121 \times 0,0+1,554 \times 1,0=1,554 \mathrm{t} / \mathrm{m}^{3}$

Calculando-se o peso específico aparente para um tempo de 50 anos (vida útil econômica) a partir do valor de $\mathrm{K}$, tem-se:

$$
\begin{gathered}
\mathrm{K}=0,2563 \times 0,0+0,0913 \times 0,0+0,0 \times 1,0=0,0 \\
\gamma_{T}=1,554+0,0 \times 50=1,554 \mathrm{t} / \mathrm{m}^{3}
\end{gathered}
$$

O resultado, como não podia deixar de ser, indica que a areia não se compacta com o tempo. Para este trabalho foi adotado o valor do peso específico aparente como $1,5 \mathrm{t} / \mathrm{m}^{3}$. Então:

$$
\gamma_{\text {ap }}=1,5 \mathrm{t} / \mathrm{m}^{3}
$$




\section{Cálculo do volume anual de sedimento retido e do tempo de assoreamento}

Considerando os dados acima, o valor anual de sedimento retido $\mathrm{S}$ e o tempo de assoreamento do reservatório $\mathrm{T}$ foram calculados como:

$$
\begin{gathered}
\mathrm{S}=\frac{990.975 \times 0,50}{1,5}=330.325 \mathrm{~m}^{3} / \mathrm{ano} \\
\mathrm{T}=\frac{4,8 \times 10^{6}}{330.325}=14 \text { anos }
\end{gathered}
$$

\section{Cálculo do tempo de assoreamento do volume morto do reservatório}

Através das mesmas fórmulas e utilizando o volume morto do reservatório, tem-se:

$$
\mathrm{T}=\frac{3,9 \times 10^{6}}{330.325}=12 \text { anos }
$$

\section{AUMENTO DO TRANSPORTE DE SEDIMENTOS NO CURSO D’ÁGUA}

Os anos próximos de 1980 apresentaram grandes transformações na região devido à expansão da área agrícola, o que provocou o recrudescimento da erosão das terras. Foi nessa época que houve formações de grandes voçorocas em São Gabriel do Oeste, situada na bacia vizinha, do rio Taquari. Isso, inclusive, induziu organizações internacionais a colaborarem na reconstituição dos terrenos e na orientação para o manejo adequado dos solos.

Para a verificação dessa evolução da erosão, através da análise do transporte de sedimentos no curso d'água, foram utilizados os mesmos dados de descarga líquida e descarga sólida total do posto do Rio Itiquira a montante da Estrada BR-163. Foram preparadas duas outras curvaschave de sedimentos, sendo a primeira para os anos de 1979/1980 (Figura 5) e a segunda para os anos de 1981/1982 (Figura 6).

Utilizando-se as equações correspondentes e os dados da série de vazões mensais foram obtidos os valores médios de vazões anuais e descargas sólidas anuais que, a seguir, foram acumulados, conforme mostrado na Tabela 4.

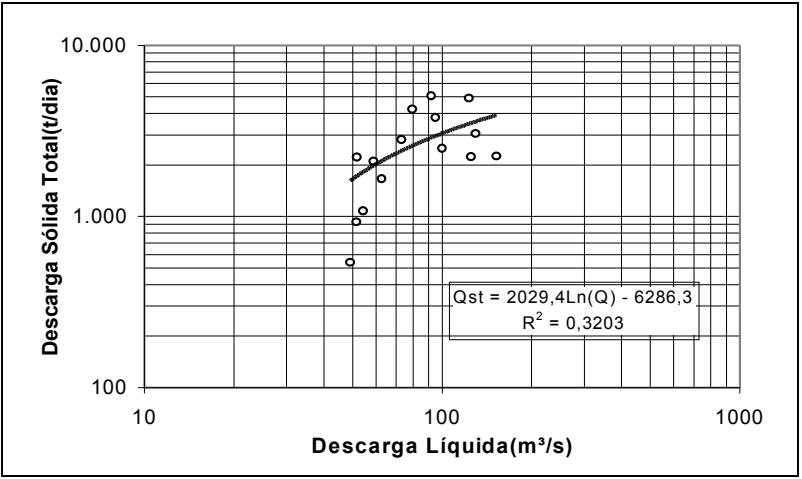

Figura 5. Curva-chave de sedimentos totais em Itiquira - período 1979/1980.

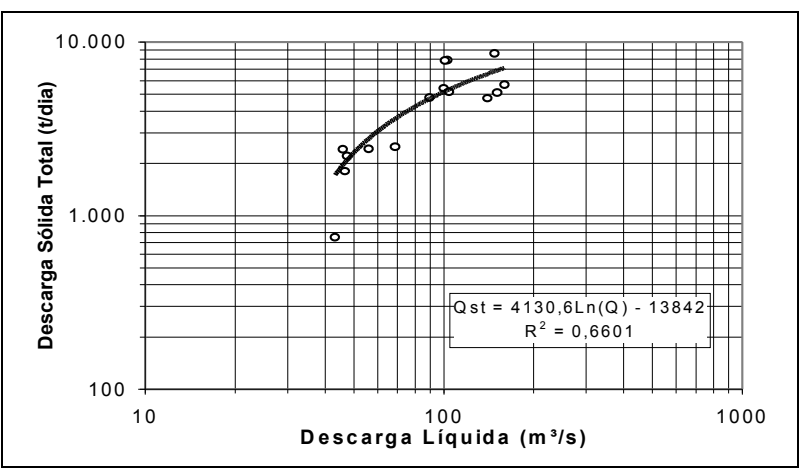

Figura 6. Curva-chave de sedimentos totais em Itiquira - período 1981/1982.

Tabela 4. Valores de vazões e carga sólida acumuladas (1979/1982).

\begin{tabular}{ccccc}
\hline Anos & Vazões & $\begin{array}{c}\text { Vazões } \\
\text { Acumul. } \\
\left(\mathrm{m}^{3} / \mathrm{s}\right)\end{array}$ & $\begin{array}{c}\text { Descargas } \\
\text { Sólidas } \\
(\mathrm{t} / \mathrm{dia})\end{array}$ & $\begin{array}{c}\text { Desc. Sóli- } \\
\text { das Acumul. } \\
(\mathrm{t} / \mathrm{dia})\end{array}$ \\
\hline 1979 & 112,1 & 112,1 & 3.036 & 3.036 \\
1980 & 109,1 & 221,2 & 3.040 & 6.075 \\
1981 & 88,3 & 309,5 & 4.473 & 10.548 \\
1982 & 88,3 & 397,8 & 4.374 & 14.923 \\
\hline
\end{tabular}

Os dados de vazões e descargas sólidas acumuladas foram então utilizados para traçar a respectiva curva de massa. A partir da observação dessa curva, apresentada na Figura 7, pode-se concluir que o transporte de sedimento no curso d'água aumentou no período de 1979 a 1982, evidenciando o incremento de erosão na bacia devido a ações antrópicas.

A taxa de variação do transporte de sedimento pode ser calculada a partir das razões entre as descargas sólidas e vazões correspondentes como: 


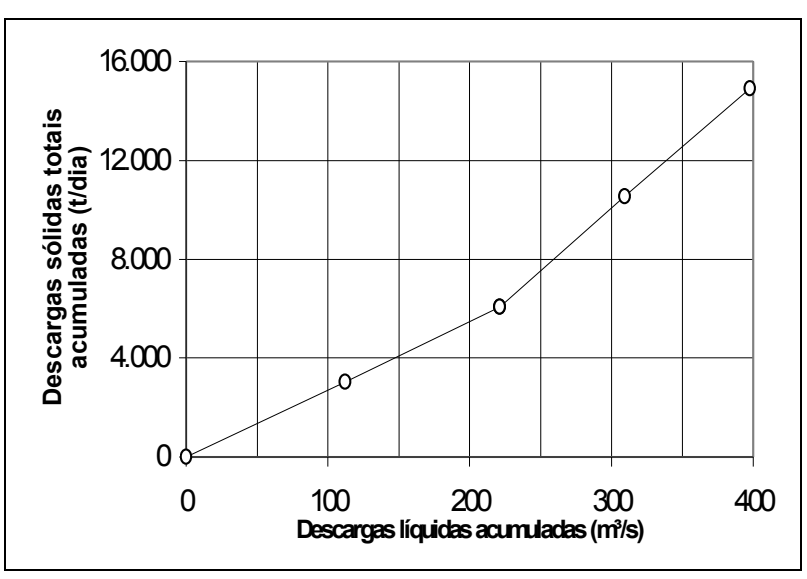

Figura 7. Curva de massa de sedimentos para o Itiquira (1979/1982).

$$
\begin{aligned}
& r_{1}=\frac{3 \cdot 036+3 \cdot 040}{112,1+109,1}=27,5 \\
& r_{2}=\frac{4.473+4 \cdot 374}{88,3+88,3}=50,1
\end{aligned}
$$

Então:

$$
E_{c}=\frac{r_{2}-r_{1}}{r_{1}}=0,82
$$

Isso significa que houve um aumento do transporte de sedimento de $82 \%$ entre 1979 e 1982, valor muito alto que pode comprometer o reservatório com um assoreamento muito rápido.

O cálculo da taxa anual, considerando a pequena amostragem de 4 anos, é feito com a seguinte equação:

$$
\left(1+R_{i}\right)^{4}=1,82
$$

o que resulta para o aumento anual de transporte de sedimento $\left(R_{i}\right)$ o valor de $16,15 \%$.

Aplicando essa taxa ao período de 17 anos, entre 1982 e 1999 ter-se-ia um aumento no volume de sedimento depositado de $330.325 \mathrm{~m}^{3}$ /ano para $3.624 .506 \mathrm{~m}^{3} / \mathrm{ano}$, conforme demonstrado na Tabela 5.

Os valores acumulados indicam que ao final desse período o sedimento acumulado alcançaria $24.021 .914 \mathrm{~m}^{3}$ e que o volume total do reservatório, de $4,8 \times 10^{6} \mathrm{~m}^{3}$, ficaria assoreado em menos de 9 anos, caso a citada taxa de crescimento se mantivesse constante.

Caso a descarga de sedimentos prevista para o ano de 1999 pudesse ser confirmada através de medições locais, o cálculo teria que ser
Tabela 5. Volume de sedimento acumulado no reservatório com o aumento do transporte de sedimento.

\begin{tabular}{ccc}
\hline Ano & $\begin{array}{c}\text { Volume de } \\
\text { Sedimentos } \\
\left(\mathrm{m}^{3} / \mathrm{ano}\right)\end{array}$ & $\begin{array}{c}\text { Sedimento } \\
\text { Acumulado } \\
\left(\mathrm{m}^{3}\right)\end{array}$ \\
\hline $1^{\circ}-1983$ & 330.325 & 330.325 \\
$2^{\circ}-1984$ & 383.672 & 713.997 \\
$3^{\circ}-1985$ & 445.636 & 1.159 .633 \\
$4^{\circ}-1986$ & 517.606 & 1.677 .239 \\
$5^{\circ}-1987$ & 601.199 & 2.278 .438 \\
$6^{\circ}-1988$ & 698.293 & 2.976 .731 \\
$7^{\circ}-1989$ & 811.067 & 3.787 .798 \\
$8^{\circ}-1990$ & 942.054 & 4.729 .852 \\
$9^{\circ}-1991$ & 1.094 .196 & 5.824 .048 \\
$10^{\circ}-1992$ & 1.270 .909 & 7.094 .957 \\
$11^{\circ}-1993$ & 1.476 .161 & 8.571 .117 \\
$12^{\circ}-1994$ & 1.714 .560 & 10.285 .678 \\
$13^{\circ}-1995$ & 1.991 .462 & 12.277 .140 \\
$14^{\circ}-1996$ & 2.313 .083 & 14.590 .223 \\
$15^{\circ}-1997$ & 2.686 .646 & 17.276 .869 \\
$16^{\circ}-1998$ & 3.120 .539 & 20.397 .408 \\
$17^{\circ}-1999$ & 3.624 .506 & 24.021 .914 \\
\hline
\end{tabular}

realizado com 0 volume de sedimentos de $3.624 .506 \mathrm{~m}^{3} / a n o$, o que resultaria num tempo de assoreamento total de apenas 15 meses.

\section{CONCLUSÕES E RECOMENDAÇÕES}

Este estudo sedimentológico concluiu que o tempo de assoreamento do reservatório de Itiquira seria de 14 anos, se a carga sólida não tivesse aumentado com o tempo. Considerando o aumento dessa carga à taxa de $16,15 \%$ ao ano, chegou-se à conclusão que o reservatório pode ser assoreado totalmente em menos de 9 anos. Em relação ao volume morto, aquele tempo reduzir-se-ia de 12 anos para menos que 8 anos. De qualquer forma, conclui-se que a vida útil do aproveitamento seria muito curta, o que poderia, até mesmo, inviabilizar o empreendimento, face à necessidade de dragagens que possibilitassem a sua continuidade operacional.

Para que isso seja evitado, recomenda-se a previsão do controle de sedimento através de dispositivo que venha a descarregar automaticamente os depósitos que se formarão na área pró- 
xima da tomada d'água. Isso pode ser feito através de um vertedouro com soleira mais baixa, desde que essa estrutura situe-se próxima da captação, ou de um descarregador de fundo adequadamente posicionado. É certo que nenhuma dessas opções permitiria a descarga de todo o sedimento do lago mas evitaria que a entrada da tomada d'água ficasse comprometida por depósito de sedimentos.

A operação do descarregador de fundo deve ocorrer periodicamente, de forma a manter a comporta livre de depósitos que possam ocasionar seu empenamento. Naturalmente, essa periodicidade deverá ser aumentada nos períodos chuvosos.

Considera-se também necessário que o canal de adução disponha de um desarenador adequadamente posicionado, que pode ser um trecho plano com um rebaixamento no final. Adicionalmente deverá dispor de uma válvula que permita escoar a areia depositada. Esse desarenador é importante para eliminar o sedimento grosso que poderia alcançar as turbinas e provocar abrasão.

Outros estudos de previsão poderiam ser feitos. Por exemplo: como os sedimentos se distribuiriam no reservatório; em que tempo os depósitos alcançariam a tomada d'água; como seria a formação do delta e o seu avanço no lago; quanto de sedimento se depositaria no volume útil, etc. Considerando o pequeno tempo de vida útil obtido, inferior ao tempo de vida útil econômica do aproveitamento, esses estudos se tornam desnecessários porque não melhorariam as conclusões.

A estação Montante da Estrada BR-163, situada no rio Itiquira, encontra-se desativada desde 1990, quando da extinção do DNOS. É evidente que a continuidade do monitoramento da estação teria subsidiado com melhores dados os estudos sedimentológicos.

\section{REFERÊNCIAS}

ANNANDALE, G. W. (1987). Reservoir Sedimentation. Elsevier Science Publishers B. V. Amsterdam.

CARVALHO, N. O. (1994). Hidrossedimentologia Prática. CPRM e ELETROBRÁS. Rio de Janeiro, RJ.

ICOLD (1989). Sedimentation control of reservoirs Guidelines. International Commission on Large Dams. Paris.

ITICON (1998). Aproveitamento hidrelétrico Itiquira. Otimização do projeto básico. Relatório do Consórcio IESA/INTERTECHNE. Rio de
Janeiro, RJ. (ITICON - Consórcio Construtor Itiquira)

MORRIS, G. L. \& FAN, J. (1997). Reservoir sedimentation handbook. McGraw-Hill. New York, NY.

STRAND, R. I. (1974). Design of small dams: Sedimentation. Appendix H. US Bureau of Reclamation. Washington, DC.

VANONI, V. A. (1977). Sedimentation Engineering. ASCE, American Society of Civil Engineers. New York, NY.

\section{Sedimentation of a Small Reservoir - Itiquira, a Case Study}

\section{ABSTRACT}

There are several differences between the sedimentation behaviour of a small reservoir and a large reservoir. In the latter, flow velocities are low, leading to the deposition of sands and part of the suspended load. Higher velocities and small capacity result in the deposition of coarse sediment, while the finer part of the load is discharged through the spillway and pipes. However, sediment is deposited much faster in the small reservoir due not only to its small capacity, but also because the dam is usually constructed in the upper course of rivers, where slopes are steeper and there is heavier precipitation leading to larger sediment loads per unit drainage area. Therefore, small reservoirs must be carefully designed in order to ensure the adequate operation of its intake and sediment must be controlled.

This paper presents the study of sediment deposition for the Itiquira Hydroelectric Power Plant in Mato Grosso, a state of Brazil, estimating a service life of only twelve years. This implies that an adequately located bottom outlet and settling basin should be included in its design. 